\title{
Economic Recessions and Infant Mortality in the U.S., 1999-2008
}

\author{
David Bishai", Qingfeng Li and Sai Ma
}

\author{
Department of Population, Family, and Reproductive Health, Johns Hopkins Bloomberg School of Public \\ Health, 615 N. Wolfe St., Baltimore, MD 21205, USA
}

\begin{abstract}
Objectives: Prior studies of US data from the 1990s have shown that economic growth is associated with higher all cause mortality. This paper updates prior findings to more recent data on US infant mortality for blacks and whites.

Methods: We analyzed data from 50 US states from 1999 to 2008 using state fixed-effects regression models stratified to identify the racially disparate impact of each state's economic performance on infant mortality, controlling for state policy-related variables, reflecting population, \% black, \% on TANF, \% on Medicaid, and alcohol consumption.

Results: Economic recessions are significantly associated with lower post-neonatal mortality for white infants, but not black infants. Each 1\% decrement a state's gross state product, would be associated with an approximately 2.3 fewer infant deaths (95\% Cl: $-0.294-4.894)$ in an average state with 64,000 total births. Results were robust to the inclusion of state trends, national trends, state fixed effects, lagged gross state product, and the inclusion of measures of unemployment and state policy variables.

Conclusions: This study in combination with studies from the 1990s reflects growing evidence that economic growth in the US can be harmful to child health. Policy makers need to be informed and mindful about the "side effects" of economic growth on health.
\end{abstract}

Keywords: Infant mortality, economics, recession, racial disparity, USA.

\section{INTRODUCTION}

U.S. infant mortality rates fell steadily throughout the $20^{\text {th }}$ century due to improvements first in public health, sanitation, economic status and later in medical technology [1, 2]. There is controversy on the role that economic growth played in the fall of infant mortality in the early 1900s. Some see economic growth in the early $20^{\text {th }}$ century as critical to enable improvements in housing, nutrition, and sanitation credited with better population health $[3,4]$. Others stress that the connection between economic growth and health was not automatic during this era and required the presence of public health reformers [5].

Currently, the causes of infant death have shifted from primarily infectious to primarily non-infectious conditions like congenital anomalies, sudden infant death, and injury in the U.S. [6]. Furthermore the overall connection between macroeconomic performance and population health is known to weaken as incomes rise [7, 8]. Emerging findings suggest that in modern economies the relationship between economic booms and population health is largely negative [9-12]. The correlation between economic growth and higher mortality has been found for the US [10, 12], European countries [11, 13-15] Japan [16], and Latin America [17]. A statistically significant inverse

*Address correspondence to this author at the Department of Population, Family, and Reproductive Health, Johns Hopkins Bloomberg School of Public Health, 615 N. Wolfe St., Baltimore, MD 21205, USA; Tel: 410-955-7807;

Fax; 410-955-2303; E-mail: dbishai@jhsph.edu relationship was originally shown between US state rates of unemployment and deaths from heart disease, automobile crashes, flu/pneumonia, liver disease, homicide, infant mortality, and neonatal mortality for data spanning 1972 to 1991 [9]. Ruhm's (2013) reanalysis of US state mortality data from 1976 to 2009 shows that the relationship between macroeconomics and health changes by time period and by cause of death [18]. From 2000 to 2009 cardiovascular deaths remain procyclical, cancer deaths have switched to becoming countercyclical, and accidental poisoning deaths have emerged as a critical countercyclical contributor to mortality [18]. In the past, public health scientists had suspected that economic booms could be harmful to health [19]. Findings from high and middle income countries remain counterintuitive for those steeped in the prior era of wealth-sensitive infectious disease mortality [20]. We are now in an era where effects appear to be shifting over time and by cause of death. More understanding will rely on regularly updating the knowledge base of findings on macroeconomics and health.

Ruhm's (2000) analysis of unemployment and mortality was replicated for US state data on infant mortality from 1975 to 1999 and effects were found to be statistically significantly different between whites and blacks [21]. A $1 \%$ increase in state unemployment lowered infant mortality by $0.56 \%$ for whites and by $0.93 \%$ for blacks [21]. The racial disparity was interpreted in part as reflective of compositional 
differences in women giving birth-during economic downturns vulnerable black mothers were more likely to opt out of childbearing, whereas in downturns vulnerable white mothers were more likely to opt into childbearing [21]. For both races, economic downturns were associated with earlier and more consistent prenatal care [21]. Ruhm's (2013) study did not examine infant mortality, so an update of research in this area using more recent data is called for to see if the effects seen prior to 2000 remain intact [18].

This paper uses more recent data on state economic performance and infant health to update the analysis and to examine whether racial disparities in the response to economic booms have narrowed. We are not testing whether infant mortality gaps have narrowed: they have not [22]. Instead we are testing whether blacks and whites have become more similar in the response of infant mortality rates to economic growth. There are several reasons for optimism that there is increasing racial similarity in the response to economic growth. Black women, unlike black men, have experienced improved success in the US labor market relative to whites since the year 2000. As a result, over the last decade the relative gap in median earnings between black women and black men closed from $84 \%$ to $93 \%$. Black women's median earnings in 2012 are now $86 \%$ as high as white women. In addition, focused policy efforts over the last 10 years have made racial gaps in first trimester prenatal care smaller than ever, with black mothers estimated to have first trimester prenatal care at $86 \%$ the frequency of white mothers. These modest improvements in economic options for black women may have led to greater similarity in the timing of births during an economic downturn for vulnerable mothers. Furthermore, improvements in access to health care for black women may have homogenized responses to health seeking during economic booms. To determine whether blacks and whites have become more similar in their response to economic booms, we applied state fixed effects models to on state gross domestic product (GSP) for the US from 1999 to 2008, and state level race-specific infant mortality, neonatal mortality, and post neonatal mortality.

\section{METHODS}

\section{Data}

The dependent variables are state-level count measures of infant mortality, neonatal mortality, and postneonatal mortality, obtained from Center for
Disease Control (CDC)'s National Center for Health Statistics (NCHS) website. We used the data from 1999 to 2008. The final analytical sample includes ten years of data from 50 states.

We stratified the analysis by time of infant death. Neonatal mortality rates reflect deaths in the first 28 days and indicate different epidemiological processes from post neonatal mortality rates (for deaths from 29 to 365 days). The former would be more reflective of prematurity, low birth weight, and congenital anomalies, whereas the latter would be more composed of acquired conditions, sudden infant death and injuries. Inasmuch as the impact of prematurity on mortality can be altered by access to health care and health care access is a function of employment and state Medicaid policies that could be mediated by state economic growth, we will control for the generosity of state Medicaid programs in the relationship between state GSP and neonatal mortality. Inasmuch as injuries may be affected by parental supervision, an economic boom may lead to deficits in supervision and a potential connection between state GSP and neonatal mortality. We also included state level alcohol consumption because alcohol use is known to increase during economic booms.

Two measures of state economic performance that have been studied most for their relationship with health are the state unemployment rate and the state gross domestic product (GSP). In practice these two variables are tightly correlated, and according to macroeconomic theory, the variation of these variables over time is reflecting different aspects of the same underlying process of the business cycle. Because of the collinearity of unemployment and GSP, we ran separate models for each variable, but did not include them simultaneously. We selected control variables guided by a consideration of factors that would mediate the effect of GSP on infant health. Table 1 shows the variables used in the analyses. We included the proportion of the state population that was black because of prior literature showing that this variable had differential effects on population health by race [23]. We included measures of the percent of the population receiving Temporary Assistance for Needy Families (TANF) to control for fluctuations in states TANF generosity that may have been related to state economic performance. For similar reasons we included the percent of the population on Medicaid. The total number of births is included to control for economy induced fluctuations in women's decisions to carry a pregnancy to term. 
Table 1: Description of Variables Used in Analysis. Sample Size is 500 State-Years Data are from 50 US States Over 10 Years from 1999 to 2008

\begin{tabular}{|c|c|c|}
\hline & Mean & (SD) \\
\hline White neonatal deaths & 113 & $(128)$ \\
\hline White postneonatal deaths & 58 & $(66)$ \\
\hline White total deaths & 172 & $(192)$ \\
\hline White infant mortality rate (deaths/1000) & 5.9 & $(0.9)$ \\
\hline Black neonatal deaths & 244 & $(272)$ \\
\hline Black postneonatal deaths & 122 & $(135)$ \\
\hline Black total deaths & 366 & $(405)$ \\
\hline Unemployment rate & 4.815 & $(1.37)$ \\
\hline Gross state product or GSP (log) & 25.615 & $(1.05)$ \\
\hline Annual change gross state product GSP (log) & 0.051 & $(0.03)$ \\
\hline Growth rate of gross state product (GSP) & 0.053 & $(0.03)$ \\
\hline Per capita growth rate of gross state product (GSP) & 0.044 & $(0.03)$ \\
\hline Births (thousands) & 64,505 & $(77,037)$ \\
\hline$\%$ of total population that are African American & 8.800 & $(8.95)$ \\
\hline$\%$ of population receiving TANF & 1.529 & $(0.87)$ \\
\hline$\%$ of population with Medicaid & 14.191 & $(4.27)$ \\
\hline Alcohol consumption in thousands of gallons & 1880 & $(382)$ \\
\hline Population & $5,828,079$ & $(6,409,280)$ \\
\hline
\end{tabular}

\section{Statistical Analysis}

We used fixed effects models filter out the confounding effects of unobservable features of states that were constant. Stratified models for blacks and whites were modeled separately as:

$$
\begin{aligned}
& \log \left(\text { Death } \text { Count }_{i j t}\right)=C+\beta_{1} G S S P_{j t}+\beta_{2} X_{j t}+\beta_{3} P p_{j t}+ \\
& \beta_{4} T_{t}+\beta_{5} T_{j t}+\mu_{j}+\varepsilon_{j t}
\end{aligned}
$$

Where Death Count $_{\mathrm{jit}}$ is the count of deaths measured for the $\mathrm{i}$-th racial group in the $\mathrm{j}$-th state at time t. GSP is the gross state product of the j-th state at time t. $X_{j t}$ is a set of state-level policy variables for $j$-th state at time that might be confounded with GSP. $\mathrm{Pop}_{\mathrm{jt}}$ is a set of three variables conveying the total population of each state, the number of births of each state and the proportion of the population that were African American. An alternative specification would have been to put IMR, or (the ratio of infant deaths to births) as the dependent variable, however this can unintentionally create spurious findings if the total population in the denominator of the dependent variable is correlated with independent variables. The problem would be compounded if the model included GSP per population on the right side of the regression. That is why the model includes GSP not GSP per capita. Keeping population count and births on the right side of the regression as independent variables avoids this threat to validity and helps us interpret the coefficient on GSP as the effect of economic growth on infant death counts, holding population fixed. $T_{t}$ is a national time trend. $T_{\mathrm{jt}}$ is a state specific time trend. The term $\mu_{\mathrm{j}}$ is the state level fixed effect, and $\varepsilon_{\mathrm{jt}}$ is a random error term. The model imposes a state fixed effect $\mu_{j}$ and random error term $\varepsilon_{j \mathrm{jt}}$. We use a fixed effects model to eliminate the confounding effect of $\mu_{\mathrm{j}}$ by transforming the dependent and all independent variables as deviations from their 10-year averages. Because different states contributed different numbers of births to the sample the variance of the estimated death counts is not uniform. We used analytic weights proportional to each state's population so that larger states with higher populations exposed to economic fluctuations counted more in the estimates than smaller states that contributed fewer births to the analysis. Because mortality after birth may be partially affected by maternal environment during pregnancy, we also explored models in which GSP and unemployment rates were lagged one year.

\section{RESULTS}

Table 1 shows that the white infant mortality rate during this period was 5.9 deaths per 1000. Expressed 
as count data there was an average of 172 white infant deaths per year with a minimum of 17 (West Virginia, 2008) and a maximum of 2,232 (California 2005). The sample average of the logged GSP was 25.60 with a standard deviation of 1.05 . The unweighted average of 50 state's proportion African American in Table 1 at $8.8 \%$ is lower than the actual proportion African American in the US population as a whole.

Table 2 summarizes the results of the fixed-effect multivariate models with a state-specific trend included.

A higher log of GSP is found to be associated with higher odds of infant death in whites. A one unit increase in log GSP would be associated with an excess of 232 infant deaths. (95\% Cl: $-28,492)$, of which there would be 150 post-neonatal deaths $(95 \%$ $\mathrm{Cl}$ : -4.0, 305.64). This coefficient can be interpreted to state that a $1 \%$ increment in the GSP would be associated with 2.32 incremental infant deaths and 1.5 incremental post-neonatal deaths in whites.
States that expanded TANF to more people were experiencing higher infant deaths. Medicaid had no significant independent effect on mortality after controlling for all other variables. The coefficient on the number of births was positive and highly significant, and this simply signifies that the number of births is performing well to control for how many infants are being exposed to the chance of dying in each stateyear studied. There were no statistically significant effects of GSP on black infant, neo-natal or postneonatal deaths.

We tested the robustness of our findings in several ways (Table 3 ). Models where GSP was not transformed by logs led to the same pattern of findings as shown in Table 2 and these models are available from the authors. Models with unemployment taking the place of GSP (not shown in tables) demonstrated that higher unemployment led to lower odds of death for whites in the post-neonatal period. The effects of GSP

Table 2: Results of Fixed Effects Panel Regressions of the State Counts of Death by Infant Age and Race for US 1999 to 2008. Regressions Weighted by Population

\begin{tabular}{|c|c|c|c|c|c|c|}
\hline & \multicolumn{3}{|c|}{ White } & \multicolumn{3}{|c|}{ Black } \\
\hline & Infant Deaths & $\begin{array}{l}\text { Neonatal } \\
\text { Deaths }\end{array}$ & $\begin{array}{c}\text { Post } \\
\text { Neonatal } \\
\text { Deaths }\end{array}$ & Infant Deaths & $\begin{array}{l}\text { Neonatal } \\
\text { Deaths }\end{array}$ & $\begin{array}{c}\text { Post } \\
\text { Neonatal } \\
\text { Deaths }\end{array}$ \\
\hline \multirow[t]{2}{*}{ Gross Domestic Product(log) } & $232.013^{*}$ & 81.195 & $150.818^{*}$ & 58.785 & 54.250 & 4.613 \\
\hline & [1.788] & [1.285] & [1.958] & [1.184] & [1.200] & [0.161] \\
\hline \multirow[t]{2}{*}{$\%$ of total population that are African American } & $-3.254^{* *}$ & $-4.118^{\star *}$ & 0.864 & -3.253 & -2.470 & -0.782 \\
\hline & {$[-2.257]$} & {$[-2.042]$} & [0.674] & {$[-1.350]$} & {$[-1.591]$} & {$[-0.847]$} \\
\hline \multirow[t]{2}{*}{$\%$ of Population receiving TANF } & $18.134^{\star *}$ & 11.435 & $6.699^{* * *}$ & $15.845^{\star * *}$ & $15.682^{\star * \star}$ & 0.170 \\
\hline & [2.533] & [1.662] & [4.365] & [2.718] & [2.789] & [0.059] \\
\hline \multirow[t]{2}{*}{$\%$ of population with Medicaid } & -2.107 & -1.978 & -0.129 & $-1.632^{*}$ & -0.852 & -0.782 \\
\hline & {$[-1.279]$} & {$[-1.371]$} & {$[-0.223]$} & {$[-1.746]$} & {$[-1.210]$} & {$[-1.316]$} \\
\hline \multirow[t]{2}{*}{ Alcohol consumption per capita in gallons } & -0.144 & -0.105 & -0.040 & $-0.091^{*}$ & -0.046 & $-0.045^{\star * *}$ \\
\hline & {$[-1.209]$} & {$[-1.211]$} & {$[-0.856]$} & {$[-1.685]$} & {$[-1.076]$} & {$[-3.016]$} \\
\hline \multirow[t]{2}{*}{ Population } & 0.000 & -0.000 & 0.000 & -0.000 & 0.000 & $-0.000^{\star *}$ \\
\hline & {$[0.264]$} & {$[-0.187]$} & [0.695] & {$[-0.840]$} & [0.761] & {$[-2.336]$} \\
\hline \multirow[t]{2}{*}{ Births } & $0.005^{\star \star *}$ & $0.004^{* * *}$ & 0.000 & $0.006^{* * *}$ & $0.003^{* *}$ & $0.003^{* * *}$ \\
\hline & [4.730] & [6.029] & [1.360] & [3.639] & [2.285] & [4.025] \\
\hline \multirow[t]{2}{*}{ Unemployment rate FE } & 3.521 & 3.520 & 0.001 & 1.120 & 0.497 & 0.621 \\
\hline & [1.331] & [1.150] & {$[0.001]$} & {$[0.557]$} & [0.292] & {$[0.560]$} \\
\hline \multirow[t]{2}{*}{ Constant } & $59.396^{* *}$ & $29.161^{*}$ & $30.235^{*}$ & 9.974 & 12.631 & -2.658 \\
\hline & [2.147] & [1.951] & [1.685] & {$[0.511]$} & {$[0.717]$} & {$[-0.246]$} \\
\hline Observations & 500 & 500 & 500 & 500 & 500 & 500 \\
\hline R-squared & 0.581 & 0.508 & 0.352 & 0.371 & 0.306 & 0.255 \\
\hline
\end{tabular}

Note: ${ }^{*}$ indicates $p<0.1,{ }^{* *} p<0.05,{ }^{* * *} p<0.01$ ? 
Table 3: Robustness Analysis to Alternative Models

\begin{tabular}{|c|c|c|c|c|c|c|c|c|c|}
\hline \multirow[b]{3}{*}{ Fixed Effects Model Includes: } & \multicolumn{3}{|c|}{$\begin{array}{l}\text { Model Includes State } \\
\text { Trends }\end{array}$} & \multicolumn{3}{|c|}{$\begin{array}{c}\text { Model Includes National } \\
\text { Trends }\end{array}$} & \multicolumn{3}{|c|}{ Model Includes No Trends } \\
\hline & \multicolumn{2}{|c|}{ GSP Effects On } & \multirow[b]{2}{*}{ PNMR } & \multicolumn{2}{|c|}{ GSP Effects On: } & \multirow[b]{2}{*}{ PNMR } & \multicolumn{2}{|c|}{ GSP Effects On: } & \multirow[b]{2}{*}{ PNMR } \\
\hline & IMR & NNMR & & IMR & NNMR & & IMR & NNMR & \\
\hline GSP & & & W & & & W & & & W \\
\hline Unemployment and GSP & W & & W & W & & W & & & W \\
\hline Unemployment Lagged One Year and GSP & & & W & W & & W & & & W \\
\hline GSP Lagged One Year & & & W & & & W & & & \\
\hline Unemployment and GSP Lagged 1 year & & & W & & & W & & & W \\
\hline \multirow[t]{2}{*}{ Unemployment Lagged $1 \mathrm{Yr}$ and GSP Lagged $1 \mathrm{yr}$} & & & W & & & W & & & W \\
\hline & & \multicolumn{2}{|c|}{$\begin{array}{l}\text { Includes State } \\
\text { Trends }\end{array}$} & & \multicolumn{3}{|c|}{ Includes National Trends } & $\begin{array}{l}\text { No } \\
\text { Trends }\end{array}$ & \\
\hline
\end{tabular}

"W" denotes significant coefficient in white infants. Blanks denote no significant effect on whites or blacks.

on post-neonatal mortality deaths in whites was robust to whether the models used national trends or state trends. Results were robust to the whether either one or both GSP and unemployment were lagged one year. We did not find any macroeconomic effects on black infant, neonatal, or post-neonatal deaths in any of the robustness tests.

\section{DISCUSSION}

Our analysis of data from 1999-2008 showed that increases in the economic performance of a state measured by a higher GSP or a lower unemployment rate were correlated with higher infant mortality for whites but not for blacks. The mortality effects are significant in the post-neonatal period, but not the neonatal period and are robust to multiple specifications of the models. Past discussion of this association has focused on several mechanisms including changes in parental behaviors [21, 24], selective changes the composition of women giving birth [21], and even air pollution [25].

Our analysis has been about reassessing racial disparities in the GDP effect and has not focused on a deep exploration sorting out the various pathways. Noting that the harmful effects of economic growth are larger in the post neonatal period supports the predominance of parental safety behavior and air pollution as mediators of the relationship.

In contrast to studies of this phenomenon using data from 1975 to 1999, our study of more recent data shows a reversal of the racial differences in the effects of economic growth. Prior research argued that the associations between infant mortality and socioeconomic status are different in different racial/ethnic groups and therefore should be studied separately [26]. Whereas data from 1975 to 1999 showed that the harmful effects of economic growth were twice as large in black infants as white infants, our analysis failed to find any effects of economic growth on black infants.

The absence of harmful effects of economic growth on black infant health is a new finding and may reflect changes in African-American families. The improvements since the 1990s of black women's educational attainment and their stronger connection to the labor market may have altered the former connection of black families to the performance of the economy.

\section{LIMITATIONS}

The analysis is constrained by the number of states and years. However, we were able to construct a study design with 50 states observed from 1999-2008, which allows us to examine changes in infant mortality rates within each state over 10 years while controlling for time and state characteristics. A potential threat to the fixed effects specification would be time-varying unobservable confounders at the level of the state that are simultaneously correlated to child health and to GSP. We show robustness of the GSP effect to whether or not observed confounding variables are included in the analysis. This suggests, but doesn't prove that there would be robustness to unobservable confounders as well.

US policy makers and politicians who emphasize economic growth as the leading goal of social policy 
need to be mindful about the unwanted consequences of single-minded pursuit of this goal. Our results suggest a need to mitigate the harmful health consequences of economic growth. Most Americans would prioritize the health and survival of their children as a strong motivation for wanting more money. This analysis in combination with many past studies reflects growing certitude that economic growth in the US remains detrimental to child survival. It's time for Americans to have a serious discussion with their leaders about the goals that matter.

\section{ACKNOWLEDGEMENTS}

Dr. Bishai's participation on this project was funded by the Gates Foundation through Grand Challenge 13, Population Health Metrics, to the universities of Harvard, Johns Hopkins, MIT and Queensland. No potential conflicts of interest and corporate sponsors are reported. The authors are grateful for helpful comments received from Dr. Ashley Schempf and Dr. Bernard Guyer.

The authors are grateful for research assistance from Laura Prichett MacAllister.

\section{COMPETING INTERESTS}

No competing interests to declare.

\section{AUTHORS' CONTRIBUTIONS}

Sai Ma conducted the data analysis, contributed to the interpretation of the data, and helped draft the paper.

Qingfeng $\mathrm{Li}$ contributed to the data collection, analysis and participated in drafting the paper.

David M Bishai contributed to the conception and design of the study, supervised data collection, rafted the paper, and contributed to the data analysis and interpretation.

\section{REFERENCES}

[1] Collins WJ, Thomasson MA. Exploring the Racial Gap in Infant Mortality Rates 1920-1970. NBER Working Paper Series 2002; 8836.

[2] Cutler DM, Meara E. Changes in the Distribution of Mortality over the 20th Century. NBER Working Paper 2001; 8556.

[3] Mckeown T. The Modern Rise of Population. New York: Academic Press 1976.

[4] Fogel RW, Costa DL. A theory of technophysio evolution, with some implications for forecasting population, health care costs, and pension costs. Demography 1997; 34(1): 49-66. http://dx.doi.org/10.2307/2061659
[5] Szreter S. Rethinking McKeown: the relationship between public health and social change. Am J Public Health 2002; 92(5): 722-5.

http://dx.doi.org/10.2105/AJPH.92.5.722

[6] Singh G, Yu SM. US Childhood Mortality, 1950 through 1993: Trends and Socioeconomic Differentials. AJPH 1996; 86(4): 505-19.

http://dx.doi.org/10.2105/AJPH.86.4.505

[7] Omran A. The Epidemiological Transition Theory. A Preliminary Update. Journal of Tropical Pediatrics 1983; 29: 305-16.

http://dx.doi.org/10.1093/tropej/29.6.305

[8] Preston $\mathrm{SH}$. The Changing Relation between Mortality and Level of Economic Development. Population Studies 1975; 29(2): 231-48.

[9] Ruhm CJ. Are Recessions Good for Your Health? Quarterly Journal of Economics 2000; 115(2): 617-50. http://dx.doi.org/10.1162/003355300554872

[10] Tapia Granados JA. Increasing mortality during the expansions of the US economy, 1900-1996. Int J Epidemiol 2005; 34(6): 1194-202. http://dx.doi.org/10.1093/ije/dyi141

[11] Gerdtham UG, Ruhm CJ. Deaths rise in good economic times: evidence from the OECD. Econ Hum Biol 2006; 4(3): 298-316.

http://dx.doi.org/10.1016/i.ehb.2006.04.001

[12] Ruhm CJ. Good times make you sick. J Health Econ 2003; 22(4): 637-58. http://dx.doi.org/10.1016/S0167-6296(03)00041-9

[13] Granados JA. Recessions and Mortality in Spain, 1980-1997. European Journal of Population 2005; 21: 393-422. http://dx.doi.org/10.1007/s10680-005-4767-9

[14] Gerdtham UG, Johannesson M. Business cycles and mortality: results from Swedish microdata. Soc Sci Med 2005; 60(1): 205-18.

http://dx.doi.org/10.1016/j.socscimed.2004.05.004

[15] Neumayer E. Recessions lower (some) mortality rates: evidence from Germany. Soc Sci Med 2004; 58(6): 1037-47. http://dx.doi.org/10.1016/S0277-9536(03)00276-4

[16] Granados JA. Macroeconomic fluctuations and mortality in postwar Japan. Demography 2008; 45(2): 323-43. http://dx.doi.org/10.1353/dem.0.0008

[17] Miller G, Urdinola BP. Cyclicality, Mortality, and the Value of Time: The Case of Coffee Price Fluctuations and Child Survival in Colombia. Journal of Political Economy 2010; 118(1): 113-55. http://dx.doi.org/10.1086/651673

[18] Ruhm CJ. Recesssions, Healthy No More? NBER Working Paper Series 2013; 19287.

[19] Szreter S. Rapid economic growth and 'the four Ds' of disruption, deprivation, disease and death: public health lessons from nineteenth-century Britain for twenty-firstcentury China? Trop Med Int Health 1999; 4(2): 146-52. http://dx.doi.org/10.1046/j.1365-3156.1999.00369.x

[20] Brenner MH. Commentary: economic growth is the basis of mortality rate decline in the 20th century--experience of the United States 1901-2000. Int J Epidemiol 2005; 34(6): 121421. http://dx.doi.org/10.1093/ije/dyi146

[21] Dehejia R, Lleras-Muney. Booms, Busts, and Babies' Health Quarterly Journal of Economics 2004; 119(3): 1091-130. http://dx.doi.org/10.1162/0033553041502216

[22] Orsi JM, Margellos-Anast H, Whitman S. Black-White health disparities in the United States and Chicago: a 15-year progress analysis. Am J Public Health 2010; 100(2): 349-56. http://dx.doi.org/10.2105/AJPH.2009.165407 
[23] Bird ST. Separate black and white infant mortality models: differences in the importance of structural variables. Soc Sci Med 1995; 41(11): 1507-12. http://dx.doi.org/10.1016/0277-9536(95)00029-7

[24] Ruhm CJ. Economic conditions and health behaviors: are recessions good for your health? N C Med J 2009; 70(4): 328-9.

[25] Knittel C, Miller D, Sanders N. Caution drivers! Children present: Traffic, Pollution, and Infant Health. NBER Working Paper Series 2011; 17222.
[26] Stockwell EG, Goza FW. Racial differences in the relationship between infant mortality and socioeconomic status. J Biosoc Sci 1996; 28(1): 73-84. http://dx.doi.org/10.1017/S0021932000022094

[27] Bishai DM. Infant mortality time series are random walks with drift: are they cointegrated with socioeconomic variables? Health Econ 1995; 4(3): 157-67.

http://dx.doi.org/10.1002/hec.4730040302

Received on 27-12-2013

Accepted on 26-02-2014

Published on 10-03-2014

http://dx.doi.org/10.6000/1929-4247.2014.03.01.8

(C) 2014 Bishai et al.; Licensee Lifescience Global.

This is an open access article licensed under the terms of the Creative Commons Attribution Non-Commercial License (http://creativecommons.org/licenses/by-nc/3.0/) which permits unrestricted, non-commercial use, distribution and reproduction in any medium, provided the work is properly cited. 